\title{
Case series and exposure series: the role of studies without controls in providing information about the etiology of injury or disease
}

\author{
Peter Cummings, Noel S Weiss
}

\begin{abstract}
Descriptions of exposure histories in persons with the same injury or illness ("case series"), and descriptions of outcomes in persons with the same exposure ("exposure series"), have the potential to contribute knowledge relevant to disease etiology in some special situations. The case series can be thought of as a primitive form of case-control study-one in which the controls are only implied. Similarly, the exposure series is a rudimentary type of cohort study. By keeping these analogies in mind, those who author or read studies without controls can assess the design or results for selection bias, confounding, or information bias. While studies without controls cannot supplant true case-control or cohort studies, they are relatively cheap and easy to perform, and there are circumstances in which they provide valuable information. Attention to design is needed to strengthen the results they provide.

(Injury Prevention 1998;4:54-57)
\end{abstract}

Keywords: epidemiology; case-control study; cohort study; case series

Exposure histories of persons with the same injury or illness ("case series") are frequently reported in the medical literature because it is relatively easy for physicians to collect and classify patients according to their injury or disease. Occasional medical reports appear in which outcomes are described for a group of persons who all have a common exposure. We know of no accepted term for such a report and have chosen to call these "exposure series". This type of study is much less common, probably because it is often difficult to identify or collect persons by their exposure history. Case series and exposure series share two features: they are study designs that have no formal comparison group, and they are generally held, as we will describe below, in low esteem as a method for clarifying disease etiology.

Our purpose here is to point out that studies without controls do sometimes contribute valuable knowledge about etiology. Case series have done this often, both in the past and in the modern era. It is useful to think of the case series as a primitive form of case-control study, and doing so can help clarify the situations in which case series can shed light on etiology. Similarly, an exposure can be usefully thought of as a primitive form of cohort study.

Etiologic studies that use controls offer many advantages over uncontrolled studies. Our goal is not to encourage uncontrolled studies, but to describe the occasional circumstances in which they are informative and to note the potential biases that should be considered when a group of cases or exposed individuals is reported.

\section{Case series}

Several textbooks that describe epidemiologic study designs make no mention of case series. ${ }^{1-6}$ Others give case series only the briefest mention, mainly to note their limitations. ${ }^{7-11}$ Some authors classify case series as "descriptive" studies, ${ }^{12} 13$ distinguishing them from analytic designs such as the case-control study, cohort study, or clinical trial. It has been argued that the case series is generally suitable only for generating hypotheses that must later be confirmed by analytic studies. ${ }^{12-14}$

However, a few authors have noted the similarity between case series and case-control studies. ${ }^{15-17}$ In a case series, the cases and their exposures are described explicitly, while the frequency of exposure in non-cases is implied but not mentioned. The implied control group is everyone else in the hypothetical population from which the cases were derived. Examples from the literature clarify this idea and serve to illustrate how case series have made contributions to knowledge about the etiology of disease.

\section{SCROTAL CANCER}

In the 18th century, Sir Percivall Pott wrote his famous description of scrotal cancer, which he called "the chimney-sweeper's cancer". ${ }^{18}$ Pott did not actually describe a series of cases, but made it clear that nearly all the cases he had seen were in chimney sweeps. In a later edition of Pott's book, published after his death, Sir James Earle pointed out that soot was the probable culprit and he described the case of Allan Spragg, a gardener who sprinkled soot to kill slugs and developed cancer on the skin of his hand. ${ }^{19}$ The work of Pott and Earle, in which the cases are barely described and controls are never
Center, Box 359960, 325

Ninth Avenue, Seattle, WA 98104-2499, USA. 
mentioned, correctly identified risk factors for scrotal cancer. If all men in the 1770 s were chimney sweeps or had heavy soot exposure, Pott and Earle would never have published their observations. But it was obvious to them that the exposure history of the cases was greatly different from that of the general population, and this led them to conclude that the exposure was a cause of the disease.

\section{MENINGOCOCCAL MENINGITIS}

Weichselbaum, in 1887, reported a series of 10 patients who died of meningitis. ${ }^{20} \mathrm{He}$ noted that four of the patients had meningeal pus infected with pneumococcus, an organism that had been previously reported in association with meningitis. But in the other six cases he identified a new Gram negative organism with a peculiar biscuit shape. This case series identified what would later be called Neisseria meningitidis and established this organism as a cause of meningitis. Weichselbaum did not mention controls in his paper, but he knew that meningeal pus and inflammation were rare findings at autopsy.

SNOWMOBILE CRASHES AND ALCOHOL

Among 108 snowmobile drivers who died in snowmobile crashes in Ottawa, Canada, during 1985 through 1990, 79 (73\%) had alcohol in their blood and $71(65 \%)$ were intoxicated by Ottawa's legal standard. ${ }^{21}$ We regard this as strong evidence that alcohol use is associated with snowmobile crashes, since it seems unlikely that any reasonable selection of control snowmobile drivers would find that two thirds were legally intoxicated. (The authors of the Ottawa report attempted to generate relative risk estimates by using automobile drivers killed in traffic crashes as controls. We think this is a poor choice since deceased car drivers may not represent the population of snowmobile drivers and are themselves a population known to have a high prevalence of recent alcohol use. ${ }^{22}$ )

ADULTERATED RAPESEED OIL POISONING

In May 1981, thousands of patients were hospitalized in Spain with a new type of pneumonia; ultimately over 20000 cases were reported and there were over 300 deaths. $^{23-25}$ Investigators found that afflicted infants at Niño Jesús Hospital in Madrid had all consumed adulterated rapeseed oil, which was sold illegally as cooking oil. This observation was made at other hospitals as well, and on June 10 the government issued a warning about the oil. The cause of this new disease was correctly identified and appropriate action initiated before the etiology was confirmed by a case-control study, which only started on June $11 .^{26}$

\section{Exposure series}

In a cohort study, subjects are classified by their exposure status. Usually those with exposure are compared with those who are not exposed, but sometimes all subjects are exposed to some degree and those with greater exposure are compared with those with less. We define an exposure series as a study in which all the subjects are uniformly exposed, so there is no formal comparison group with a lower level of (or no) exposure in the study. For such a study, the implied comparison is with the experience of non-exposed persons in the population from which the exposed persons are selected. Exposure series are unusual enough in the medical literature that we had to invent a name to describe them and we had difficulty finding examples to illustrate their use.

Dunn and colleagues examined the possibility that HIV could be transmitted from mother to child through breast milk. ${ }^{27}$ They summarized data from four studies in which children were breast fed by mothers who had acquired HIV infection postpartum and estimated that the risk of transmission was $29 \%$ (95\% confidence interval $16 \%$ to $42 \%$ ). These results, based solely on exposed patients, provide strong evidence that vertical transmission of HIV is possible through breast milk, since other studies suggest that the risk of HIV transmission within families through casual contact is near zero. ${ }^{28-30}$

\section{Advantages of considering a case series as a type of case-control study}

Thinking of a case series as a case-control study with implicit controls has several advantages. First, this view makes it easier to understand why the case series, a reputedly weak design, has played an important role in the understanding of disease etiology, both historically and in modern times. If the diseaseexposure association is very strong, it may require nothing but an implied control group to detect its presence.

Second, the case-control design, rather than being a recent and somewhat mysterious invention of epidemiologists, has been used intuitively by physicians for over two centuries. The modern case-control study is an extension of the case series in which the frequency of exposure among controls is made explicit.

Third, the author and reader of a case series can better assess the results by examining them for the biases that can affect any case-control study. Selection bias, in which cases are chosen because they are both diseased and exposed, can create a false association between exposure and disease in a case series. Information bias is another potential problem. It can arise when great effort goes into eliciting the exposure history of cases, while the frequency of exposure among the implied controls is assumed to be common knowledge. Confounding, in which the relationship between disease and exposure is distorted by another factor, can be difficult to prevent or even assess in a case series. Analytic studies often can control confounding in their analysis, but this technique generally cannot be applied in a case series.

Possible biases can sometimes be addressed in the report of a case series and doing this may clarify the likelihood that the reported association is real. For example, selection bias arises if the exposure of interest has an important effect on the likelihood of the case appearing in 
a series, independent of the exposure's effect on the occurrence of injury or disease. Several studies have reported that among victims of assault seen in emergency departments, from $17 \%$ to $70 \%$ have detectable alcohol in their blood or breath. ${ }^{31}$ However, it seems likely that aside from the injuries that a person might suffer after an altercation, the presence of alcohol might influence the decision to come to the emergency department. Friends or medics might be concerned that the victim's slurred speech could be due to brain injury, rather than alcohol, or they might insist on transport to the hospital because otherwise the beating victim would sleep in the street. If these events occur, persons who are beaten while intoxicated will be more likely to come to the emergency department than persons who are beaten while sober, even if their physical injuries are the same. The result will be that even if intoxication is not associated with injury, intoxicated persons will be over-represented among emergency department assault victims. One remedy for this bias would be to limit the cases to persons injured so severely that they would have come to an emergency department regardless of their degree of intoxication.

Sometimes confounding can be addressed in a case series. Holcomb reported that among 270 drivers who were hospitalized after a crash in Evanston, Illinois, during 1935 through $1937,46 \%$ had been drinking. ${ }^{32}$ Because of this seemingly high prevalence, Holcomb hypothesized that alcohol was a cause of many crashes. However, he noted that the incidence rate of crashes per vehicle on the road was greater at night, when people were more likely to drink, and he asked whether the hazard of driving in darkness could explain the apparent association between alcohol use and traffic crashes. Although he had information regarding cases and controls, numerical methods to deal with confounding in this type of data would not be published for another 20 years. ${ }^{15}$ Instead, Holcomb used data from his cases and pointed out that if the problem were reduced visibility in the dark, one would expect crash incidence to remain relatively constant during the night; but, the incidence rate of crashes per vehicle was over twice as high in the two hours after midnight, compared with the two hours before midnight, coinciding with the time when intoxicated drivers would leave bars and be on the road.

All of the advantages that are gained by keeping in mind the case-control design when considering a case series, seem to apply equally well to thinking of the exposure series as a rudimentary form of cohort study. In their assessment of breast feeding as a means of HIV transmission, Dunn and coworkers gave special attention to the problem of selection bias, excluding cases in which the exposure was recognized because of the presence of disease. ${ }^{27}$

\section{Situations in which studies without controls may be useful}

Because a comparison group is not explicitly defined in case or exposure series, these studies are probably only useful under the following conditions:

(1) When the relative risk for disease associated with a given exposure is very large, then the frequency of exposure or disease among the subjects can be recognized as aberrant. Small to moderate relative risks, which can be readily detected by a conventional case-control or cohort study, are hard to identify in studies without explicit controls. For several case series, from which etiologic inferences have been drawn, virtually all the cases were exposed. For example, Pott claimed he never saw a case of scrotal cancer except in chimney sweeps. ${ }^{18}$ None the less, if an exposure is uncommon in the population from which the cases are derived, the investigator may recognize the association between exposure and disease even when only a fraction of the cases are exposed. Similarly, for exposure series, the etiologic importance of an exposure may be appreciated even if only some of those exposed develop disease, provided the disease outcome is sufficiently rare among unexposed members of the source population.

(2) For some exposures the frequency is so well known in the population that even a modest increase in relative risk can be detected by a case series. Sex is one example of such an "exposure". If an author reports a case series of 100 children with injuries and notes that $75 \%$ are boys, we may surmise that the relative risk for this disease is threefold higher in boys than girls, because any potential source population will be almost evenly divided between the sexes.

Sometimes the authors of a case series know very clearly the population from which the cases are derived, and are in a position to estimate the exposure experience of the source population, using data from other sources. For example, Diekema and coauthors used this strategy in a study of epilepsy as a risk factor for drowning. ${ }^{33}$ They identified all new cases of unintentional death due to submersion among children in King County, Washington, and compared the prevalence of epilepsy in this group $(6.3 \%)$ with the estimated prevalence among other children in the same county $(0.5 \%)$, which they obtained from a study in Oklahoma: the relative risk was $13.8(95 \%$ confidence interval 7.0 to 27.0 ). This strategy should be used judiciously. The estimates obtained are plausible to the degree that: the cases are clearly representative of those that occurred in the source population; the ascertainment of exposure is the same for cases and controls; and there is little difference in the true frequency of exposure between the population of interest and that for which the data are available.

\section{Conclusion}

Although studies without controls can be usefully thought of as the most primitive form of case-control or cohort studies, their weaknesses should be recognized. They usually cannot provide a numerical estimate of relative risk and as a rule can only detect strong associa- 
tions. Just as for studies with controls, reports of case series and exposure series can be strengthened if their authors address the issues of selection, confounding, and information bias. Studies without controls have the advantage of being relatively inexpensive in time and money. Under certain circumstances, they can produce etiologic insights. Even with 200 years of hindsight, we do not feel compelled to criticize Sir Percivall Pott for having failed to assess the frequency of chimney sweeping in controls.

This work was supported in part by grant T32 CA 09168 from the National Cancer Institute and grant R49/CCR002570 from the Centers for Disease Control and Prevention.

1 MacMahon B, Pugh TF. Epidemiology: principles and methods. Boston: Little, Brown, 1970.

2 Kleinbaum DG, Kupper LL, Morgenstern H. Epidemiologic research: principles and quantitative methods. New York: Van Nostrand Reinhold, 1982.

3 Mausner JS, Kramer S. Mausner \& Bahn: epidemiology—an introductory text. Philadelphia: WB Saunders, 1985.

4 Rothman KJ. Modern epidemiology. Boston: Little, Brown, 1986.

5 Hernberg S. Introduction to occupational epidemiology. Chelsea, MI: Lewis Publishers, 1992.

6 Lilienfeld DE, Stolley PD. Foundations of epidemiology. 3rd Ed. New York City: Oxford University Press, 1994.

7 Fletcher RH, Fletcher SW, Wagner EH. Clinical epidemiology: the essentials. 2nd Ed. Baltimore: Williams and epidemiology: the

8 Elwood JM. Causal relationships in medicine: a practical system for critical appraisal. Oxford: Oxford University Press, 1988. for critical appraisal. Oxford: Oxford University Press, 1988. Checkoway H, Pearce N, Crawford-Brown DJ. Research
methods in occupational epidemiology. New York: Oxford methods in occupational

10 Gordis L. Epidemiology. Philadelphia: WB Saunders, 1996

11 Weiss NS. Clinical epidemiology: the study of the outcome of illness. 2nd Ed. New York: Oxford University Press, 1996 $106-7$

12 Kelsey JL, Thompson WD, Evans AS. Methods in observational epidemiology. New York City: Oxford University Press, 1986: 4-8.

13 Hennekens $\mathrm{CH}$, Buring JE. Epidemiology in medicine. Boston: Little, Brown, 1987: 106-8.
14 Sackett DL, Haynes RB, Guyatt GH, et al. Clinical epidemiology: a basic science for clinical medicine. 2nd Ed. epidemiology: a basic science for clinical
Boston: Little, Brown, 1991: 290-1.

15 Mantel N, Haenszel W. Statistical aspects of the analysis of data from retrospective studies. F Natl Cancer Inst 1959;22: $719-48$

16 Sartwell PE. Retrospective studies. A review for the clinician. Ann Intern Med 1974;81:381-6.

17 Schlesselman JA. Case-control studies: design, conduct, analysis. New York: Oxford University Press, 1982.

18 Pott P. The chirurgical works of Percivall Pott, FRS. Dublin: James Williams, 1778 .

19 Pott P. The chirurgical works of Percivall Pott, FRS. London: Johnson, 1808.

20 Weichselbaum A. Ueber die aetiologie der akuten meningitis cerebrospinalis. Fortschr Med 1887;5:573-83.

21 Rowe B, Milner R, Johnson C, et al. The association of alcohol and night driving with fatal snowmobile trauma: a casecontrol study. Ann Emerg Med 1994;24:842-8.

22 Cummings P. Association of alcohol with fatal snowmobile accidents [letter]. Ann Emerg Med 1995;25:717.

23 Tabuenca JM. Toxic-allergic syndrome caused by ingestion of rapeseed oil denatured with aniline. Lancet 1981;ii:567-

4 Kilbourne EM, Rigau-Perez JG, Heath CW, et al. Clinical epidemiology of toxic-oil syndrome. Manifestations of a new illness. N Engl f Med 1983;309:1408-14.

25 Gilsanz V, Alvarez JL. Evolution of the alimentary toxic oil syndrome due to ingestion of denatured rapeseed oil. Arch Intern Med 1984;144:254-6.

26 Valenciano L. Follow-up on toxic pneumonia-Spain. MMWR Morb Mortal Wkly Rep 1981;30(34):436-8.

27 Dunn DT, Newell ML, Ades AE, et al. Risk of human immunodeficiency virus type 1 transmission through breastfeeding. Lancet 1992;340:585-8.

28 Mann JM, Quinn TC, Francis H, et al. Prevalence of HTLV-III/LAV in household contacts of patients with confirmed AIDS and controls Kinshasa, Zaire. $\mathcal{F} A M A$ 1986;256:721-4.

29 Fischl MA, Dickinson GM, Scott GB, et al. Evaluation of heterosexual partners, children, and household contacts of heterosexual partners, children, and househ
adults with AIDS. $¥ A M A 1987 ; 257: 640-4$.

30 Friedman LA, Kimball AW. Coronary heart disease mortality and alcohol consumption in Framingham. Am $\mathcal{F}$ Epidemiol 1986;124:481-9.

31 Cherpitel CJ. Alcohol and injuries resulting from violence: a review of emergency room studies. Addiction 1994;89:15765.

32 Holcomb RL. Alcohol in relation to traffic accidents. $\mathcal{F} A M A$ 1938;111:1076-85.

33 Diekema DS, Quan L, Holt VL. Epilepsy as a risk factor for submersion injury in children. Pediatrics 1993;91:612-16. 